\title{
Total thymectomy for thymic lymphoepithelioma-like carcinoma-report of two cases
}

\author{
Sachi Kawagishi', Naoko Ose ${ }^{1,3^{*}}$ D, Masato Minami', Soichiro Funaki ${ }^{1}$, Takashi Kanou ${ }^{1}$, Kenji Kimura ${ }^{2}$, Seiji Taniguchi ${ }^{2}$, \\ Eiichi Morii ${ }^{2}$ and Yasushi Shintani ${ }^{1}$
}

\begin{abstract}
Background: Thymic carcinoma has been classified into 12 subtypes, thymic lymphoepithelioma-like carcinoma (LELC) is a type of them, and has a pathological organization similar to that of lymphoepithelioma, an undifferentiated type of nasopharyngeal carcinoma. According to a report from the International Thymic Malignancy Interest Group (ITMIG), thymic LELC is a rare tumor and accounts for $6 \%$ of all thymic carcinoma cases. We report two cases of surgical resection for thymic LELC and perform a search of other reports of thymic LELC, and clinical manifestations and follow-up data thus obtained are summarized.
\end{abstract}

Case presentation: Two patients underwent surgical resection for thymic LELC. In both, tumors were detected in the anterior mediastinum and a total thymectomy was performed. Each was diagnosed with thymic LELC and classified in accordance with the Masaoka staging system as modified stage II. In recent examinations, one patient was doing well after undergoing total resection, whereas early recurrence of distant lymph node metastasis was noted in the other at 5 months after the total resection procedure and died thereafter from a different disease.

Conclusion: We report two cases of surgical resection for thymic LELC. A successful total resection may positively affect prognosis: thus, long-term follow-up examinations must be performed.

Keywords: Thymic lymphoepithelioma-like carcinoma, Thymus, Total thymectomy, Masaoka staging system

\section{Background}

Thymic lymphoepithelioma-like carcinoma (LELC), a thymic carcinoma that has been classified into 12 subtypes, has a pathological organization similar to that of lymphoepithelioma, an undifferentiated type of nasopharyngeal carcinoma [1]. Also like LELC of the head and neck, thymic LELC has been shown to have an association with Epstein-Barr virus (EBV) [2]. According to a report from the International Thymic Malignancy Interest Group (ITMIG), thymic LELC is a rare tumor and accounts for $6 \%$ of all thymic carcinoma cases [3], with affected patients generally showing a poor prognosis.

\footnotetext{
* Correspondence: naokoose@thoracic.med.osaka-u.ac.jp

1 Department of General Thoracic Surgery, Osaka University Graduate School of Medicine, 2-2(L5), Yamadaoka, Suita-shi, Osaka 565-0871, Japan

${ }^{3}$ Department of General Thoracic Surgery, Osaka University Graduate School of Medicine, 2-2, Yamadaoka, Suita-shi, Osaka 565-0971, Japan

Full list of author information is available at the end of the article
}

Herein, we report details of 2 patients who underwent surgical resection for thymic LELC.

\section{Case reports}

Case 1

A 65-year-old female presented with anterior chest pain and chest computerized tomography (CT) revealed a tumor in the anterior mediastinum. The size on CT images was measured at $36 \mathrm{~mm}$, and there was no evidence of infiltration into adjacent tissue; thus, a thymoma was suspected. A surgical resection procedure was scheduled for diagnostic and therapeutic purposes. Partial resection of the thymus was performed using video-assisted thoracoscopic surgery and the intraoperative diagnosis was suspected thymoma. The tumor size was $33 \times 28 \times 20$ $\mathrm{mm}$, the operation time was $64 \mathrm{~min}$, and the amount of bleeding was small. The postoperative pathological diagnosis was LELC. Histologically, tumor cells with 
edematous large and round nuclei formed a solid corded net on the background of dense lymphocyte infiltration. Immunohistochemically tumor cells were positive for Bcl2 and Cytokeratin AE1 + AE3, while infiltrated lymphocytes were positive for CD3 and CD5 and negative for CD99 (Fig. 1). Microscopic invasion into surrounding adipose fatty tissue beyond the capsular portion was noted. EB-encoded RNA in situ hybridization of the tumor was negative. We also performed 18Ffluorodexyglycose positron emission tomography/CT (FDG-PET/CT), with no abnormal accumulation seen to indicate distant metastasis.

Two months after the first operation, a total thymectomy and lymph node dissection were performed median sternotomy, with an operation time of $220 \mathrm{~min}$ and bleeding totaling $100 \mathrm{ml}$. Postoperative pathological findings revealed no tumor cells in the residual thymus and no lymph node metastasis. The TNM classification was p-T1aNOM0 stage I, while it was stage II in accordance with the Masaoka staging system. Ten months after the first operation, the patient had no recurrence and no adjuvant therapy was performed.

\section{Case 2}

Chest X-ray findings in a medical checkup examination of an 81-year-old female showed an abnormal shadow. She came to our institution and chest $\mathrm{CT}$ results revealed a tumor in the anterior mediastinum. The size on CT images was $41 \mathrm{~mm}$ and there was no apparent infiltration of adjacent tissues; thus, a thymoma was suspected. An FDG-PET/CT examination revealed uptake (SUVmax 6.5) in the tumor. A total thymectomy and pretracheal lymph node dissection were performed by a median sternotomy combined with resection of the pericardium. The operation time was $114 \mathrm{~min}$ and bleeding was $50 \mathrm{ml}$, while the tumor size was $58 \times 45 \times 26 \mathrm{~mm}$. Postoperative pathological findings revealed edematous large and round nuclei in the tumor cells, which formed a solid corded net on the background of dense lymphocyte infiltration. Microscopic invasion by the tumor into surrounding adipose tissue beyond the capsule was found, while there was no evidence of lymph node metastasis. Immunohistochemical analysis revealed tumor cells were positivity for Bcl2, CD5, and p40, while infiltrated lymphocytes were positive for CD3 and negative for CD99 (Fig. 2). EB-encoded RNA in situ hybridization of the tumor was negative. The diagnosis was thymic LELC, classified as p-T1aN0M0 stage I in the TNM classification and stage II according to the Masaoka staging system.

Five months after the operation, follow-up CT findings showed enlargement of lymph nodes in the right supraclavicular fossa, right axillary region, and right mandibular, as well as mediastinal lymph nodes. FDG-PET/CT

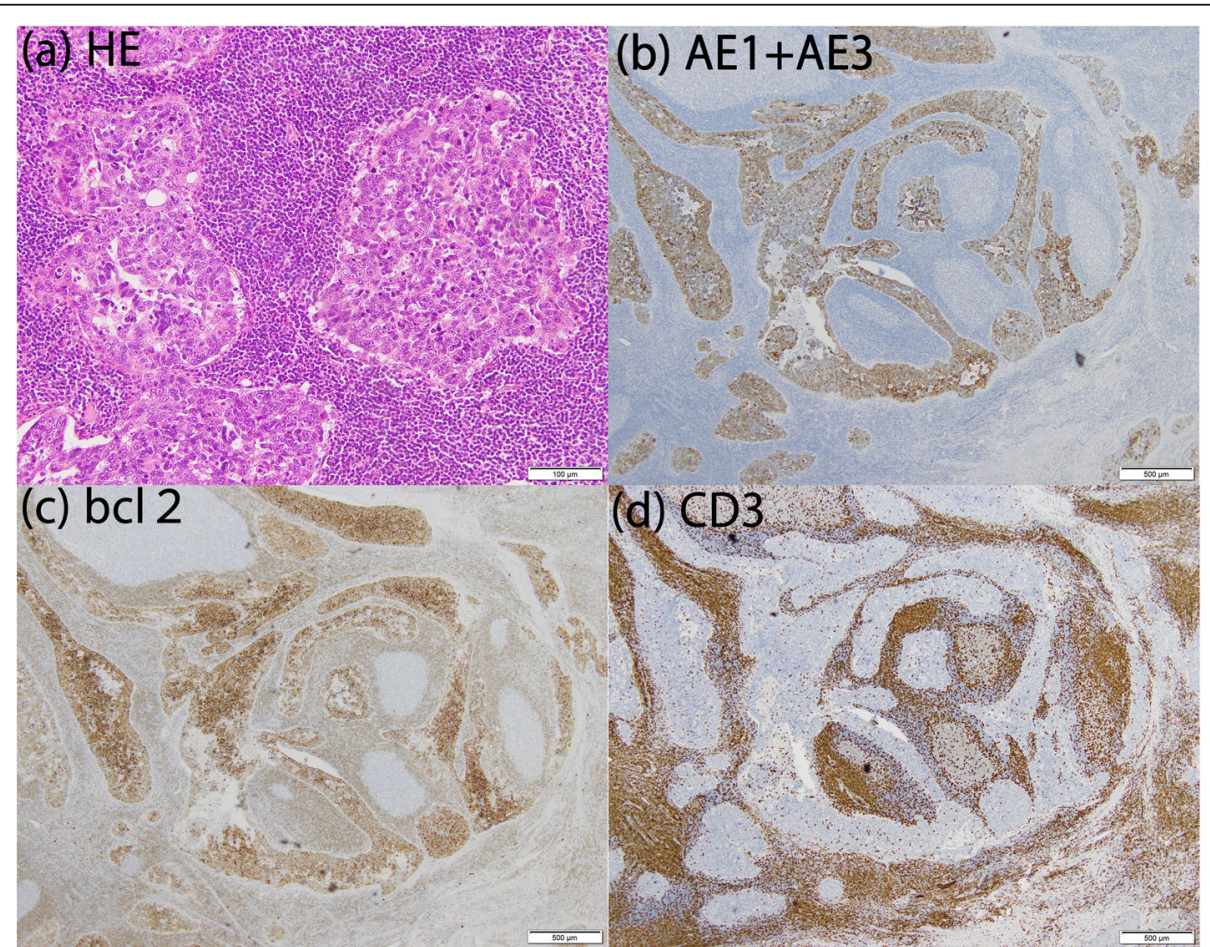

Fig. 1 Case 1. Results of HE staining and immunohistochemical analysis. a HE staining showed that the tumor cells had edematous large and round nuclei and formed a solid corded net on the background of dense lymphocyte infiltration. Thymic disease was positive for $\mathbf{b}$ cytokeratin $A E 1+A E 3$ and $\mathbf{c} B C 12$, while infiltrated lymphocytes were positive for $\mathbf{d}$ CD3 and CD5 and negative for CD99 


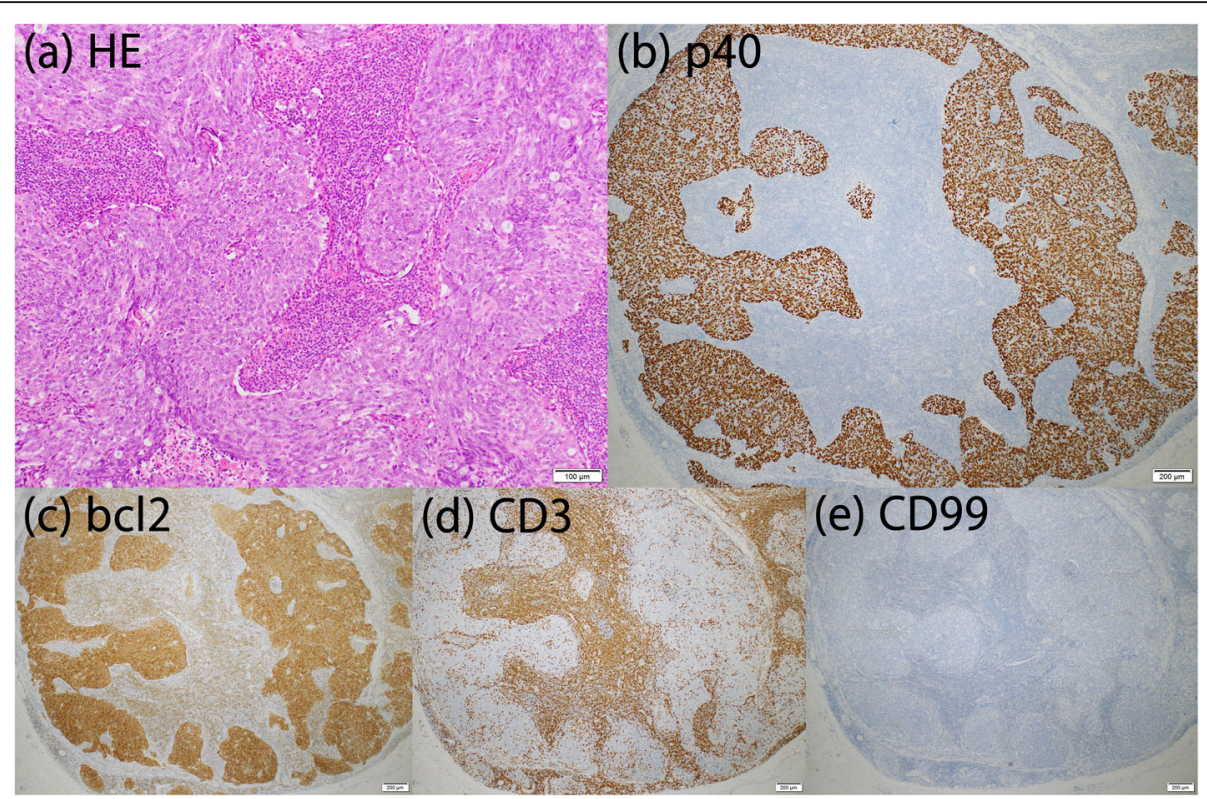

Fig. 2 Case 2. Results of HE staining and immunohistochemical analysis. a HE staining showed that the tumor cells had edematous large and round nuclei and formed a solid corded net on the background of dense lymphocyte infiltration. Thymic disease was positive for $\mathbf{b}$ p40, and $\mathbf{c}$ BCl2 and CD5, while infiltrated lymphocytes were positive for $\mathbf{d}$ CD3 and negative for e CD99

revealed uptake (SUVmax 6.6) between the chest muscles and axillary lymph node, and needle biopsy results led to a diagnosis of lymph node metastasis from thymic LELC. Chemotherapy was planned for treating metastasis. However, the patient died from another disease at 8 months after the operation.

\section{Discussion}

Shimosato initially reported thymic carcinoma in 1977 as a squamous cell carcinoma of the thymus [4], which has recently been shown to account for $14 \%$ of all thymic epithelial tumor cases $[3,4]$. According to the 2015 version of the World Health Organization classification [5], there are 12 subtypes of thymic carcinoma, including thymic LELC. This tumor has histologic features similar to lymphoepithelioma, a type of undifferentiated nasopharyngeal carcinoma. According to an ITMIG study, squamous cell carcinoma accounts for $80 \%$ of all thymic carcinoma and thymic LELC for $6 \%$ [3], while a report from the Japanese Association for Research of the Thymus (JART) noted that thymic LELC accounts for $1.3 \%$ of all thymic carcinoma cases in Japan [6]. Kondo et al. reported that thymic LELC accounts for $1.1 \%$ of all thymic carcinoma cases in Japan [7]. In our institution, there were only these 2 cases among 43 resected thymic carcinomas (4.7\%). Because of these reports, racial differences may influence an incidence of LELC, but there was no report referring to regional differences on thymic LELC.
Thymic LELC has been shown to be related to Epstein-Barr virus (EBV), while EBV has also been linked particularly to LELC of the head and neck, thymus, lung, stomach, and salivary gland [2]. Furthermore, another study reported that over $90 \%$ cases of LELC of the head and neck are EBV positive [8]. On the other hand, almost half of thymic LELC cases were found to be positive for EBV [5], lower as compared to LELC of the head and neck. The prognosis of thymic LELC patients is apparently irrespective of the presence or absence of EBV [2]. We performed EB-encoded RNA in situ hybridization of the tumors in both cases, though they were shown to be negative.

It is difficult to diagnose thymic carcinoma including thymic LELC with preoperative CT findings. In case 1 , a thymoma was suspected by preoperative CT findings. On the other hand, the tumor in case 2 had accumulation of FDG (SUVmax 6.5) on FDG-PET/CT. Previous reports indicated that a thymic carcinoma showed more increased uptake in FDG-PET than thymoma [9]. But there was no report describing differences in radiological findings of thymic LELC and other subtypes of thymic carcinoma.

We performed a search of other reports of thymic LELC, and clinical manifestations and follow-up data thus obtained are summarized in Table 1 [10-25]. The median survival time (MST) of 24 patients with a prognosis reported was 36 months. A total resection was performed for only 5 of 13 who underwent surgical treatment. Six patients including the present 2 were 
Table 1 Previous reports of thymic LELC with a summary of clinical manifestations

\begin{tabular}{|c|c|c|c|c|c|c|c|c|c|}
\hline & Reference & & Age & Sex & Symptom & $\begin{array}{l}\text { Clinical Masaoka } \\
\text { stage }\end{array}$ & Treatmemt & Recurrence & Outcome \\
\hline 1 & Taylor et al. [10] & 1988 & 43 & $\mathrm{~F}$ & Chest pain, cough & $\mathrm{IVb}$ & $R T+C T x$ & - & $28 \mathrm{~m} \mathrm{D}$ \\
\hline 2 & & & 28 & M & Chest pain & $\mathrm{IVb}$ & $\mathrm{RT}+\mathrm{CTx}$ & - & 36 m D \\
\hline 3 & Dimery et al. [11] & 1988 & 30 & $\mathrm{~F}$ & Short of breath & $\mathrm{IVb}$ & $\mathrm{RT}+\mathrm{CTX}$ & - & $24 \mathrm{~m} \mathrm{~A}^{*}$ \\
\hline 4 & Hartmann et al. [12] & 1990 & 38 & $\mathrm{~F}$ & Dyspnoea & $\mathrm{IVb}$ & $R T+C T x$ & - & $5 \mathrm{~m} \mathrm{D}$ \\
\hline 5 & & & 68 & M & $\begin{array}{l}\text { Dyspnoea, chest pain, weight } \\
\text { loss }\end{array}$ & - & $S+A R T$ & Lung & $3 \mathrm{~m} \mathrm{D}$ \\
\hline 6 & & & 46 & M & Short of breath & $\mathrm{IVb}$ & RT & - & $9 \mathrm{~m} \mathrm{D}$ \\
\hline 7 & Kuo et al. [13] & 1990 & 19 & M & Chest pain, cough & IVa & $\mathrm{S}+\mathrm{ACRT}$ & $\begin{array}{l}\text { Local recurrence, LN, } \\
\text { bone }\end{array}$ & 39 m D \\
\hline 8 & & & 41 & M & Chest pain & $\mathrm{IVb}$ & $\mathrm{S}+\mathrm{ACRT}$ & Lung, bone & 19 m D \\
\hline 9 & Fujii et al. [14] & 1993 & 13 & $\mathrm{~F}$ & None & $\mathrm{IVb}$ & $\mathrm{S}+\mathrm{ACRT}$ & Lung, dissemination & 22 m D \\
\hline 10 & Niehues et al. [15] & 1996 & 14 & M & Weight loss & - & $\mathrm{S}+\mathrm{ACRT}$ & Local recurrence, LN & $12 y A^{*}$ \\
\hline 11 & Hsu et al. [16] & 1998 & 65 & $\mathrm{~F}$ & Chest pain & - & $S+R T$ & None & $6 \mathrm{~m} \mathrm{~A}$ \\
\hline 12 & Takahashi et al. [17] & 2000 & 66 & $\mathrm{~F}$ & None & III & $S$ & Lung, dissemination & 35 m D \\
\hline 13 & Nicolato et al. [18] & 2001 & 55 & M & Chest pain, cough & IV & $C T x$ & - & - \\
\hline 14 & Yaris et al. [19] & 2006 & 16 & $\mathrm{~F}$ & Cheast pain, dyspnoea & $\mathrm{IVb}$ & $\mathrm{RT}+\mathrm{CTx}$ & - & 15 m D \\
\hline 15 & Tacyildiz et al. [20] & 2007 & 10 & M & Chest pain & III & $\begin{array}{l}\text { CTx }+S+ \\
\text { ACRT }\end{array}$ & None & $12 \mathrm{~m} \mathrm{~A}$ \\
\hline 16 & $\begin{array}{l}\text { Kilis-Pstrusinska et al. } \\
\text { [21] }\end{array}$ & 2008 & 16 & M & Cough & - & $C T x$ & - & $11 \mathrm{~m} \mathrm{D}$ \\
\hline 17 & Sekihara et al. [22] & 2014 & 14 & M & Chest pain & $\mathrm{IVb}$ & $C T x$ & - & 10 m D \\
\hline 18 & Shima et al. [23] & 2016 & 22 & M & Chest pain, dyspnoea & IVa & $\mathrm{RT}+\mathrm{CTX}$ & - & - \\
\hline 19 & Suster et al. [24] & 2018 & 55 & M & None & $\|$ & $S$ & None & $16 y$ A \\
\hline 20 & & & 57 & $\mathrm{~F}$ & Fatigue & $\|$ & S & None & $16 y \mathrm{~A}$ \\
\hline 21 & & & 55 & M & None & । & RT & - & $8 y A^{*}$ \\
\hline 22 & & & 60 & M & None & $\|$ & $\begin{array}{l}\text { No } \\
\text { treatment }\end{array}$ & - & $7 y A$ \\
\hline 23 & & & 20 & M & Cough, short of breath & IV & $\mathrm{RT}+\mathrm{CTx}$ & - & $12 \mathrm{~m} \mathrm{~A}^{*}$ \\
\hline 24 & & & 67 & $\mathrm{~F}$ & Chest pain, cough & III & $\begin{array}{l}\text { No } \\
\text { treatment }\end{array}$ & - & $1 \mathrm{~m} \mathrm{D}$ \\
\hline 25 & Pan et al. [25] & 2019 & 7 & M & Short of breath & $\mathrm{IVb}$ & $S+A C R T$ & - & - \\
\hline 26 & Our cases & & 65 & $\mathrm{~F}$ & Chest pain & $\|$ & S & None & $10 \mathrm{~m} \mathrm{~A}$ \\
\hline 27 & & & 81 & $\mathrm{~F}$ & None & $\|$ & S & LN & $7 \mathrm{~m} \mathrm{D}$ \\
\hline
\end{tabular}

$A$ alive, $A^{*}$ alive with reccurence, $A C R T$ adjuvant CRT, ART adjuvant RT, CRT chemotherapy and radiotherapy, CTx chemotherapy, $D$ dead, $F$ female, $L N$ lymph node, $m$ months, $M$ male, $R T$ radiotherapy, $S$ surgery, $y$ years

diagnosed lower than clinical Masaoka stage II, 5 patients were doing well without disease at the latest examination. Of 5 patients who underwent total resection including the 2 in the present report, findings of metastasis in the lung, pleura, and axillary lymph nodes were found in 2. Among all who underwent surgical resection, most cases of recurrence were distant metastasis as compared to local recurrence.

Treatment performed after diagnosis of recurrence of thymic LELC is generally radiation therapy and/or chemotherapy, though there is currently no standard protocol established. Chemotherapy for thymic LELC based on treatment for similar types of thymomas or nasopharyngeal carcinomas has been reported [23]. An ADOC (doxorubicin-cisplatin-vincristine-cyclophosphamide) regimen with cisplatin-anthracycline is recommended based on standard thymoma treatment strategies. A phase II study of paclitaxel and carboplatin combination chemotherapy showed that to be effective for nasopharyngeal carcinoma, with an overall response rate of $59 \%$. In our search of other reports, we noticed that thymic LELC cases are often given anthracycline- or platinum-based regimens [10,11,19-23]. On the other hand, effects of radiation therapy have not been 
reported. Previous reports indicate that thymic LELC has a poor prognosis compared to squamous cell carcinoma. But according to the ITMIG database, the survival and recurrence rates are similar to those of other types of thymic carcinoma [5] and surgical treatment is expected to improve prognosis regardless of the type of thymic carcinoma.

Each of the present cases received an early diagnosis and found to be stage II in the Masaoka staging system; thus, surgical resection was performed for both. At the most recent examinations, 1 patient was doing well without disease after undergoing a total resection, whereas the other had early recurrence of distant lymph node metastasis at 5 months after a total resection and died soon thereafter from a different disease. We consider that a successful total resection can positively affect prognosis, though the rate of recurrence rate is high even if complete resection is achieved; thus, long-term follow-up examinations must be performed.

\section{Conclusion}

We treated 2 patients for thymic LELC with surgical resection. Currently, there is no standard treatment strategy for this tumor; thus, additional case reports as well as analysis are needed.

\section{Abbreviations}

ADOC: Doxorubicin-cisplatin-vincristine-cyclophosphamide; CT: Computerized tomography; EBV: Epstein-Barr virus; FDG-PET/CT: 18F-fluorodexyglycose positron emission tomography/computerized tomography;

ITMIG: International Thymic Malignancy Interest Group; JART: The Japanese Association for Research of the Thymus; LELC: Thymic lymphoepitheliomalike carcinoma; MST: Median survival time

\section{Acknowledgements}

Not applicable.

\section{Authors' contributions}

SK described and designed the article. NO is the corresponding author. NO and YS supervised the edition of the manuscript. EM, KK, and ST performed the histopathological diagnosis. Other remaining co-authors collected the data and discussed the content of the manuscript. All authors read and approved the final manuscript.

\section{Funding}

This study was not funded.

\section{Availability of data and materials}

All data generated or analyzed during this study are included in this published article.

\section{Ethics approval and consent to participate}

The study protocol was approved by the Ethical Review Board for Clinical Studies at Osaka University (control number 10026-3).

\section{Consent for publication}

Informed consent was obtained from the patient and patient's family for the publication of this case report.

\section{Competing interests}

The authors declare that they have no competing interests.

\section{Author details}

${ }^{1}$ Department of General Thoracic Surgery, Osaka University Graduate School of Medicine, 2-2(L5), Yamadaoka, Suita-shi, Osaka 565-0871, Japan. ${ }^{2}$ Department of Pathology, Osaka University Graduate School of Medicine, 2-2, Yamadaoka, Suita-shi, Osaka 565-0871, Japan. ${ }^{3}$ Department of General Thoracic Surgery, Osaka University Graduate School of Medicine, 2-2, Yamadaoka, Suita-shi, Osaka 565-0971, Japan.

Received: 25 July 2019 Accepted: 11 September 2019

Published online: 26 October 2019

\section{References}

1. Marx A, Chan JK, Coindre JM, et al. The 2015 World Health Organization classification of tumors of the thymus: continuity and changes. J Thorac Oncol. 2015;10:1383-95.

2. lezzoni JC, Gaffey MJ, Weiss LM. The role of Epstein-Barr virus in lymphoepithelioma-like carcinomas. Am J Clin Pathol. 1995;103:308-15.

3. Huang J, Ahmad U, Antonicelli A, et al. Development of the International Thymic Malignancy Interest Group international database: an unprecedented resource for the study of a rare group of tumors. J Thorac Oncol. 2014;9:1573-8.

4. Shimosato $Y$, Kameya T, Nagai $K$, et al. Squamous cell carcinoma of the thymus. An analysis of eight cases. Am J Surg Pathol. 1977;1:109-21.

5. Travis WD, Brambilla E, Burke AP, et al. WHO classification of tumours of the lung, pleura, thymus and heart. IARC, Lyon. 2015.

6. Hishida T, Nomura S, Yano M, et al. Long-term outcome and prognostic factors of surgically treated thymic carcinoma: results of 306 cases from a Japanese Nationwide Database Study. Eur J Cardiothorac Surg. 2016; 49:835-41.

7. Kondo K, Monden Y. Therapy for thymic epithelial tumors: a clinical study of 1,320 patients from Japan. Ann Thorac Surg. 2003;76:878-84.

8. Raab-Traub N. Nasopharyngeal carcinoma: an evolving role for the EpsteinBarr virus. Curr Top Microbiol Immunol. 2015;390:339-63.

9. Ishibashi M, Tanabe $Y$, Yunaga H, et al. Usefulness of preoperative 18F-FDG PET/CT for patients with thymic epithelial tumors. Yonago Acta Med. 2019; 62:146-52.

10. Taylor HG, Butler WM, Karcher DS, et al. Thymic carcinoma: clinical findings in two patients with extrathoracic metastases. South Med J. 1998;81:664-6.

11. Dimery IW, Lee JS, Blick M, et al. Association of the Epstein-Barr virus with Iymphoepithelioma of the thymus. Cancer. 1988;61:2475-80.

12. Hartmann CA, Roth C, Minck C, et al. Thymic carcinoma. Report of five cases and review of the literature. J Cancer Res Clin Oncol. 1990;116:69-82.

13. Kuo TT, Chang JP, Lin FJ, et al. Thymic carcinomas: histopathological varieties and immunohistochemical study. Am J Surg Pathol. 1990;14:24-34.

14. Fuji T, Kawai T, Saito K, et al. EBER-1 expression in thymic carcinoma. Acta Pathol Jpn. 1993;43:107-10.

15. Niehues T, Harms D, Jürgens $H$, et al. Treatment of pediatric malignant thymoma: long-term remission in a 14-year-old boy with EBV-associated thymic carcinoma by aggressive, combined modality treatment. Med Pediatr Oncol. 1996;26:419-24

16. Hsu NY, Lin JW, Hsieh MJ, et al. Thymic lymphoepithelioma-like carcinoma associated with thymoma in a patient with ocular myasthenia. Scand Cardiovasc J. 1998;32:105-7.

17. Takahashi K, Yoshida J, Nishimura M, et al. Thymic carcinoma. Outcome of treatment including surgical resection. Jpn J Thorac Cardiovasc Surg. 2000; 48:494-8.

18. Nicolato A, Ferraresi P, Bontempini L, et al. Multiple brain metastases from "lymphoepithelioma-like" thymic carcinoma: a combined stereotacticradiosurgical approach. Surg Neurol. 2001;55:232-4.

19. Yaris N, Nas Y, Cobanoglu U, et al. Thymic carcinoma in children. Pediatr Blood Cancer. 2006;47:224-7.

20. Tacyildiz N, Ugur H, Yavuz G, et al. The coexistence of thymic carcinoma and multiple granulomas in a Turkish child. Pediatr Hematol Oncol. 2007;24: $301-7$.

21. Kiliś-Pstrusińska K, Medyńska A, Zwolińska D, et al. Lymphoepithelioma-like thymic carcinoma in a 16-year-old boy with nephrotic syndrome--a case report. Pediatr Nephrol. 2008;23:1001-3.

22. Sekihara K, Okuma Y, Kawamoto H, et al. Clinical outcome of thymic lymphoepithelioma-like carcinoma: case report of a 14-year-old male. Oncol Lett. 2014;8:2183-6. 
23. Shima H, Ozasa H, Tsuji T, et al. Response to chemotherapy with carboplatin plus albumin-bound paclitaxel in a patient with lymphoepithelioma-like thymic carcinoma: a case report. Mol Clin Oncol. 2016;4:715-8.

24. Suster D, Pihan G, Mackinnon AC, et al. Poorly differentiated nonkeratinizing squamous cell carcinoma of the thymus: clinicopathologic and molecular genetic study of 25 cases. Am J Surg Pathol. 2018;42:1224-36.

25. Pan H, Song L, Sun LR. Nephrotic syndrome: first presentation of lymphoepithelioma-like thymic carcinoma. Br J Hosp Med (Lond). 2019;80: 52-3.

\section{Publisher's Note}

Springer Nature remains neutral with regard to jurisdictional claims in published maps and institutional affiliations.

\section{Submit your manuscript to a SpringerOpen ${ }^{\circ}$ journal and benefit from:}

- Convenient online submission

- Rigorous peer review

- Open access: articles freely available online

High visibility within the field

- Retaining the copyright to your article

Submit your next manuscript at $\boldsymbol{\nabla}$ springeropen.com 